\title{
Estudio de los mecanismos de descomposición isotérmica de austenita en perlita en un acero $0,44 \mathrm{C}-0,73 \mathrm{Mn}^{(\cdot)}$
}

\author{
M. M. Aranda*, G. Pimentel*, J. Cornide* y C. Capdevila*
}

\begin{abstract}
Resumen
El objetivo de este trabajo se centra en el estudio de los mecanismos de descomposición isotérmica de la austenita en perlita en un acero de composición 0,44C-0,73 Mn. En particular, se estudia cómo afecta la temperatura de austenización ( $T^{\gamma}$ ), y por tanto, el tamaño de grano austenítico de partida (TGA), en la cinética de formación de la perlita. Se ha comprobado que existe una relación directa entre $T^{\gamma}$ y el tamaño medio de las colonias perlíticas. Por el contario, el espaciado interlaminar perlítico no depende de $T \gamma$, sino que está controlado por la temperatura de descomposición isotérmica (T), de la austenita en perlita. Finalmente se ha observado que la cinética de formación de perlita se ve acelerada para el caso de TGA pequeños y cuando el mecanismo predominante en el rango de temperaturas de trabajo es la difusión en volumen del carbono.
\end{abstract}

Palabras clave Descomposición isotérmica asutenítica; Espaciado interlaminar; Perlita divergente; Cinética de formación perlítica.

\section{Austenite-to-pearlite isothermal decomposition mechanisms in a $0.44 \mathrm{C}-0.73 \mathrm{Mn}$ steel}

Abstract

Keywords

\begin{abstract}
The goal of this paper is to determine the austenite-to-pearlite isothermal decomposition mechanisms in a $0.44 \mathrm{C}-0.73 \mathrm{Mn}$ steel. More precisely, the role of austenitizing temperature $\left(T^{\gamma}\right)$, and hence the austenitic grain size (AGS), in the kinetics of pearlite formation has been studied. Results allow us to conclude that the average size of pearlitic colonies is increased as the AGS is increased. On the other hand, it appears that the interlamellar spacing of the pearlite does not depend on the $T^{\gamma}$ but is controlled by the isothermal decomposition temperature of austenite $(T)$. Finally, it was found that formation of pearlite is triggered for small AGS values and isothermal decomposition temperature regimes where the predominant controlling mechanism is due to carbon volume diffusion.
\end{abstract}

Isothermal decomposition of austenite; Interlamellar spacing; Divergent pearlite; Kinetics of pearlitic formation.

\section{INTRODUCCIÓN}

La perlita es una estructura laminar de ferrita $(\alpha)$ y cementita $(\theta)$ que se forma a temperaturas iguales o inferiores a la temperatura del eutectoide de un acero. La austenita $(\gamma)$ transforma por un mecanismo de origen difusional, en el cual el carbono y los elementos aleantes sustitucionales se redistribuyen entre la ferrita y la cementita ${ }^{[1]}$. Los nódulos de perlita pueden nuclear en las fronteras de grano austenítico (aceros eutectoides) o en las intercaras formadas por la ferrita alotriomórfica y la austenita (aceros hipoeutectoides). En este último caso, tras la formación de ferrita, se produce un gradiente de carbono hacia el centro del grano austenítico que enriquece la austenita próxima al alotriomorfo, produciéndose en esta región la transformación perlítica ${ }^{[2]}$.

Desde el siglo XIX, se ha explotado la excelente resistencia al desgaste de los aceros de composición eutectoide y cercana a esta en la construcción de rieles de ferrocarril. Los rieles estándar presentan un valor medio de dureza Brinell (HB) entre $300 \mathrm{HB}$ y $330 \mathrm{HB}$ que se alcanza por transformación perlítica durante el enfriamiento. Para aplicaciones avanzadas, se puede aumentar la dureza de los aceros hasta valores entre 350 - $400 \mathrm{HB}$ aleándolos con elementos tales como cromo, molibdeno o vanadio.

Los alambres de acero perlítico han sido estudiados durante años debido al elevado valor del límite elástico y la resistencia a la tracción que se consiguen

(·) Trabajo recibido el día 26 de octubre de 2011 y aceptado en su forma final el día 5 de noviembre de 2011.

* Grupo Materalia - Dpto. Metalurgia Física. Centro Nacional de Investigaciones Metalúrgicas (CENIM), Consejo Superior de Investigaciones Científicas (CSIC), 28040 Madrid. 
durante el proceso de trefilado, sin que se produzca una excesiva degradación de su ductilidad y tenacidad, lo que hace que sean ideales para múltiples aplicaciones estructurales. Se ha observado que el espaciado interlaminar perlítico tiene un papel decisivo en las propiedades mecánicas de los aceros perlíti$\cos ^{[3-6]}$. Por lo tanto, profundizar en el conocimiento de los mecanismos de descomposición de la austenita en perlita resulta primordial a la hora de controlar parámetros microestructurales como el espaciado interlaminar perlítico y el tamaño de colonia perlítica, que tienen una influencia directa en las propiedades mecánicas finales de los aceros perlíticos.

Existen dos corrientes fundamentales en la literatura para explicar el mecanismo de crecimiento de perlita en un acero. Una de ellas (Hillert, Cahn, Hagel, Kirkaldy y Lundquist) sostiene que la etapa limitante de la formación de perlita es la difusión de carbono a través de la intercara austenita-perlita ${ }^{[7]}$. La difusión de carbono jugará un papel más preponderante que los elementos aleantes sustitucionales debido a su mayor difusividad en la austenita en comparación a la de estos últimos, de difusión mucho más lenta. Como resultado, los elementos aleantes sustitucionales no pueden difundir a una larga distancia durante la reacción, con lo que las condiciones de equilibrio que se mantienen en las intercaras con la austenita pueden ser de equilibrio local sin partición (ELSP) o de paraequilibrio. La diferencia entre ambos mecanismos radica en la existencia (ELSP) o no (paraequilibrio) de un pico de concentración en la propia intercara.

La otra escuela (Ridley) considera que el mecanismo de crecimiento de perlita depende de la temperatura a la cual dicha transformación tuvo lugar ${ }^{[8]}$. Así, la etapa limitante en el crecimiento de la perlita no era sólo la difusión de carbono en la austenita, sino también la difusión de los elementos sustitucionales lo que se conoce como mecanismo de equilibrio local con partición (ELCP).

En este estudio se intenta dilucidar el papel que tiene la temperatura de austenización $\left(\mathrm{T}^{\gamma}\right)$, y por tanto, el tamaño de grano austenítico de partida (TGA), en la cinética de formación de la perlita en un acero 0,44C - 0,73 Mn. Por último, es también un objetivo de este trabajo el clarificar la existencia o no de dos mecanismos de crecimiento de perlita en el acero de estudio. Para ello se realizarán medidas directas con ayuda del análisis composicional por rayos $\mathrm{X}$ en un microscopio electrónico de transmisión sobre la intercara de transformación austenita-perlita, y medidas indirectas por medio de técnicas metalográficas cuantitativas para evaluar la velocidad de formación de perlita durante un tratamiento isotérmico determinado.

\section{MATERIAL Y PROCEDIMIENTO EXPERIMENTAL}

Los tratamientos térmicos a los que se han sometido las diferentes muestras estudiadas se han realizado con ayuda del sistema de calentamiento/enfriamiento de un dilatómetro de alta resolución DT $1000^{[9]}$. Las microestructuras se han revelado utilizando diversos ataques químicos y térmicos y posteriormente se han caracterizado a partir de las curvas dilatométricas obtenidas en cada ensayo térmico realizado en el dilatómetro y con la ayuda de la microscopía óptica y electrónica de barrido y transmisión. Por último, estas microestructuras se han cuantificado mediante técnicas metalográficas convencionales y un programa analizador de imágenes.

\subsection{Material}

La composición química de la aleación estudiada se muestra en la tabla I. Se trata de un acero de tipo hipoeutectoide que contiene una fracción en peso alta de manganeso y cantidades menores de $\mathrm{Si}, \mathrm{Al}$, $\mathrm{Cr}, \mathrm{Ni}$ y $\mathrm{Ti}$.

Tabla I. Composición química del acero estudiado (\% en peso)

Table I. Composition of the studied steel (in wt.-\%)

\begin{tabular}{ccccccc}
\hline C & Mn & Si & Al & Cr & Ni & Ti \\
\hline 0,44 & 0,73 & 0,18 & 0,036 & 0,025 & 0,021 & 0,001 \\
\hline
\end{tabular}

\subsection{Tratamientos térmicos}

La figura 1 muestra la isopleta del sistema Fe-C-Mn correspondiente a una composición en manganeso igual a 0,73\% en masa, calculada con ayuda del programa termodinámico MTDATA [10]. A partir del diagrama de la figura 1 , se han diseñado tratamientos térmicos específicos para muestras con tamaños de grano extremos muy diferentes. Las temperaturas seleccionadas para los tratamientos isotérmicos están comprendidas ente $\mathrm{T}$ y $\mathrm{T}^{\prime}$, es decir, el intervalo de temperatura está comprendido entre $\mathrm{T}=715^{\circ} \mathrm{C}$ y $\mathrm{T}^{\prime}=560^{\circ} \mathrm{C}$, tal como se ha indicado en la figura 1.

En primer lugar, para estudiar el efecto del tamaño de grano austenítico de partida, TGA, en la trans- 


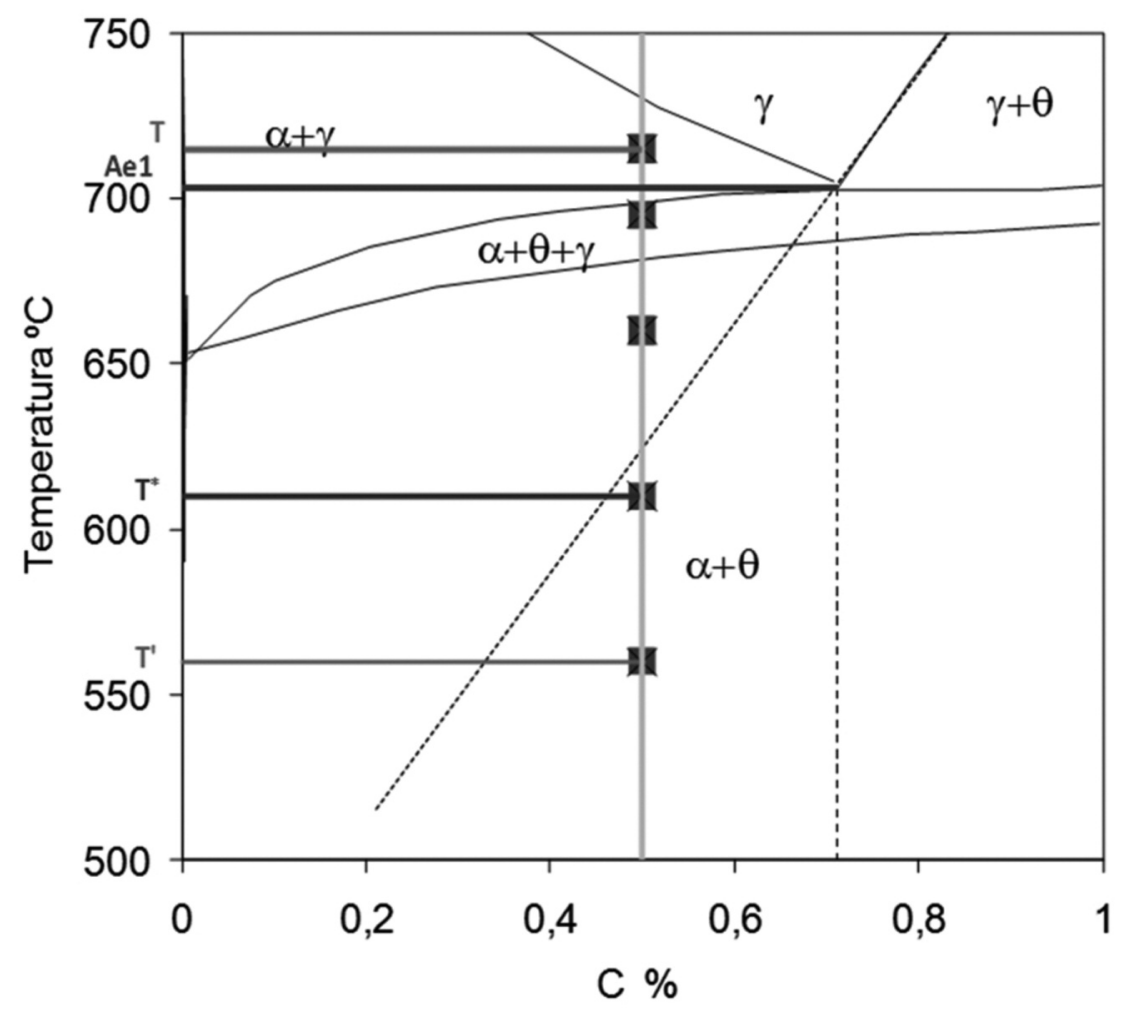

Figura 1. Diagrama de fases de un acero de composición $0,44 \mathrm{C}-0,73 \mathrm{Mn}$ donde se ha indicado el intervalo de temperaturas de descomposición isotérmica.

Figure 1. Phase diagram of a steel of 0.44C-0.73Mn composition, showing the range of isothermal decomposition temperature.

formación perlítica se determinaron dos condiciones extremas de TGA (PER-TG 1200 y PER-TG 900) como se describe en la tabla II.

Tabla II. Ensayos isotérmicos diseñados para estimar el tamaño de grano austenítico de partida

Table II. Heat treatments designed to determine the austenitic grain size

\begin{tabular}{lccc}
\hline Ensayo & $\mathbf{V c}\left({ }^{\circ} \mathbf{C} / \mathbf{s}\right)$ & $\mathbf{T Y}^{\mathrm{Y}}\left({ }^{\circ} \mathbf{C}\right)$ & $\mathbf{t}_{\mathrm{Y}}(\mathbf{s})$ \\
\hline PER-TG 1.200 & 5 & 1.200 & 120 \\
PER-TG 900 & 5 & 900 & 120 \\
\hline
\end{tabular}

Para determinar el efecto de la temperatura de descomposición isotérmica, T, en la microestructura perlítica se diseñaron los tratamientos térmicos descritos en la tabla III, tanto para muestras austenizadas a $\mathrm{T}^{\gamma}=900^{\circ} \mathrm{C}$ como para $\mathrm{T}^{\gamma}=1200^{\circ} \mathrm{C}$, siendo $\mathrm{t}=1800 \mathrm{~s}$ el tiempo que se mantuvieron las muestras a la temperatura T. En todos los ensayos de la tabla III se utilizaron los valores de velocidad de calentamiento de $\mathrm{Vc}=5^{\circ} \mathrm{C} / \mathrm{s}$ y mantenimiento a temperatura de austenización de $t_{\gamma}=120 \mathrm{~s}$, previamente indicados en la tabla II, para la etapa inicial de austenización. Finalmente, la evolución de la fracción perlítica con el tiempo se determinó por medio de ensayos interrumpidos.

\subsection{Caracterización microestructural}

a) Determinación del tamaño de grano austenítico: para determinar el tamaño de grano austenítico se ha utilizado la técnica de ataque térmico ${ }^{[11]}$. Como paso previo al tratamiento térmico se prepara una superficie pulida especularmente sobre una probeta cilíndrica de $3 \mathrm{~mm}$ de diámetro. Una vez que las muestras se han sometido al ataque térmico se visualizan y fotografían las microestructuras con un microscopio óptico Nikon EPIPHOT 200. A partir de estas micrografías se determina el tamaño de grano 
mediante el programa para analizar imágenes Image Tool ${ }^{[12]}$.

b) Determinación del tamaño de las colonias perlíticas: para la determinación del tamaño de colonia perlítica es necesario observar estas microestructuras con un microscopio electrónico de barrido (SEM). Las muestras se prepararon mediante varios ciclos de pulido y ataque ${ }^{[13}$ y 14] . El microscopio electrónico de barrido usado fue un MEB JEOL J8M6500 trabajando a $7 \mathrm{kV}$ y una distancia de trabajo (WD) de $6 \mathrm{~mm}$.

La metodología seguida para determinar el tamaño de las colonias perlíticas a partir de micrografías obtenidas en SEM es la misma que para la determinación del tamaño de grano austenítico, previamente descrito.

Para el estudio del efecto del tamaño de grano austenítico sobre el tamaño de colonia perlítica se eligieron dos muestras, 57PER y 62PER con la misma temperatura de descomposición isotérmica, $\mathrm{T}=660^{\circ} \mathrm{C}$, pero con tamaños de grano muy distintos.

c) Determinación del espaciado interlaminar de las colonias perlíticas: para la determinación del espaciado interlaminar se ha aplicado el método utilizado por Underwood ${ }^{[15]}$. Para obtener una estimación del espaciado interlaminar real medio, $\sigma_{\mathrm{o}}$, de la perlita, se recomienda medir primero el espaciado interlaminar aleatorio medio, $\sigma_{\mathrm{r}}$. Para determinar $\sigma_{\mathrm{r}}$ se superpone una rejilla circular de diámetro $\mathrm{d}_{\mathrm{r}}$ sobre una micrografía de la perlita realizada con $\mathrm{M}^{\mathrm{T}}$ aumentos y se cuenta el número de intersecciones, $\mathrm{n}_{\mathrm{r}}$, de láminas de cementita con la circunferencia.

Este procedimiento se repite en seis campos diferentes de cada micrografía y en 10 micrografías diferentes de cada muestra elegidas aleatoriamente. El espaciado interlaminar aleatorio medio viene dado por la ecuación (1):

$$
\sigma_{r}=\frac{\pi d_{r}}{M n_{r}}
$$

Saltykov ${ }^{[16]}$ demostró que para la perlita con un espaciado interlaminar constante en cada colonia, el espaciado interlaminar real medio estaría relacionado con el espaciado interlaminar aleatorio medio a través de la ecuación (2):

$$
\sigma_{0}=\frac{\sigma_{r}}{2}
$$

Para el estudio del tamaño del espaciado interlaminar se eligieron también las muestras 57PER y 62PER (Tabla III). Las micrografías fueron obtenidas mediante SEM y la metodología para preparar las muestras fue la misma que la descrita en la sec- ción anterior. Asimismo, también se estimó el espaciado interlaminar de la muestra 59PER (Tabla III) a partir de las micrografías tomadas con un microscopio electrónico de transmisión TEM JEOL 2010. Para el análisis mediante TEM es necesario seguir el siguiente procedimiento de preparación de las muestras: en primer lugar, las muestras se lijan con una lija de carburo de silicio de tamaño de grano 600 , dentro de una cubeta con agua para evitar el calentamiento de la muestra, para conseguir adelgazar la muestra hasta $0,01 \mathrm{~mm}$. En un segundo paso las muestras se someten a un electropulido. La unidad de electropulido empleada fue la Tenupol-5 a la que está acoplada un criostato de etanol Lauda RK20. La disolución de ataque usada está compuesta de $80 \%$ etanol, $15 \%$ glicerol y $5 \%$ ácido perclórico.

\section{Tabla III. Tratamientos térmicos diseñados para determinar el efecto de la temperatura de descomposición isotérmica en la microestructura perlítica}

Table III. Heat treatments designed to determine the effect of the isothermal decomposition temperature on the pearlitic microstructure

\begin{tabular}{lccc}
\hline Ensayo & $\mathbf{T}^{\mathrm{Y}}\left({ }^{\circ} \mathbf{C}\right)$ & $\mathbf{T}\left({ }^{\circ} \mathbf{C}\right)$ & $\mathbf{t}(\mathbf{s})$ \\
\hline 55PER & 1.200 & 715 & 1.800 \\
56PER & 1.200 & 695 & 1.800 \\
57PER & 1.200 & 660 & 1.800 \\
58PER & 1.200 & 610 & 1.800 \\
59PER & 1.200 & 560 & 1.800 \\
60PER & 900 & 715 & 1.800 \\
61PER & 900 & 695 & 1.800 \\
62PER & 900 & 660 & 1.800 \\
63PER & 900 & 610 & 1.800 \\
64PER & 900 & 560 & 1.800 \\
\hline
\end{tabular}

d) Determinación de la partición de elementos en la intercara perlita-austenita: El análisis del reparto de manganeso durante la transformación de la austenita en perlita, se realizó sobre láminas delgadas en un microscopio electrónico de transmisión (TEM) JEOL JEM 2010 con microanálisis por dispersión de energía Oxford Inca.

e) Determinación de la fracción volumétrica de perlita: para la determinación de la fracción volumétrica de perlita se ha empleado el método de conteo de puntos ${ }^{[17]}$. Para poder estimar la fracción de volumen de perlita se han utilizado fotografías ópticas 
representativas de la microestructura para las distintas muestras. Para poder observar dichas microestructuras, en primer lugar se lijan las muestras con lijas de carburo de silicio de grano 600 y 1.200 y después se pulen con pasta de diamante de 3 y $1 \mu \mathrm{m}$. Finalmente se atacan con nital al $2 \%$ para conseguir el revelado de las mismas durante un tiempo de ataque entre 3 y $5 \mathrm{~s}$.

También se estimó la fracción volumétrica de perlita a partir de curvas dilatométricas. Se sabe que mientras no se produzca ninguna transformación sólo se registrará la variación normal de volumen asociada a la variación de temperatura, dilatación para el calentamiento o contracción para el enfriamiento. Por el contrario, cuando la muestra sufre un cambio de fase, se produce una variación relativa de su volumen específico y como consecuencia, se registrará una anomalía en la curva en la que se puede determinar la temperatura y el tiempo en el que comienza y acaba dicha transformación de fase, pudiendo así caracterizarla.
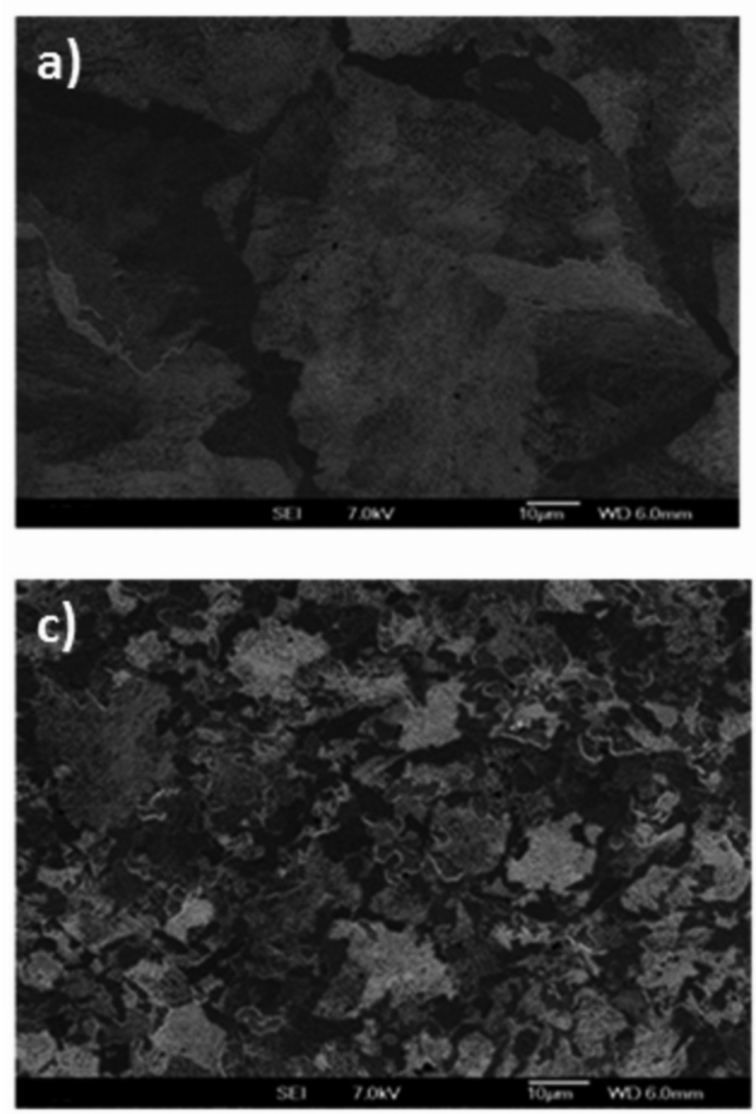

\section{RESULTADOS Y DISCUSIÓN}

\subsection{Efecto del TGA en el tamaño de colonia perlítica}

La tabla IV muestra los valores medidos del tamaño de grano austenítico, TGA, en las dos condiciones de austenización consideradas. Asimismo, la tabla V ilustra la influencia del TGA sobre la morfología de la perlita, en particular en el tamaño de las colonias perlíticas, $\mathrm{T}_{\text {colonia }}$, para la temperatura de descomposición isotérmica de $660^{\circ} \mathrm{C}$. Puede observarse claramente cómo el tamaño medio de las colonias perlíticas aumenta con la temperatura de austenización y por tanto con el tamaño de grano austenítico, como se ilustra en la figura 2. Acompañando a la micrografía SEM para cada uno de los tratamientos, se adjunta el contorno de las colonias perlíticas (Fig. 2 (b) y (d)).

Figura 2. Micrografías SEM, y el correspondiente contorno de colonias, para la determinación del tamaño de las colonias de perlita para la muestra 57PER (a y b) y 62 PER (c y d).

Figure 2. SEM micrographs, and the corresponding colonies outline, for determining the size of pearlitic colonies in the sample 57PER $(a, b)$ and $62 \operatorname{PER}(c, d)$. 
Tabla IV. Valores del tamaño de grano austenítico,TGA, para las dos temperaturas de austenización, $T^{\gamma}$

Table IV. Values of austenitic grain size, AGS, by the two austenitizing temperature, $T^{\gamma}$

\begin{tabular}{lcc}
\hline Ensayo & $\mathrm{T}_{\gamma}\left({ }^{\circ} \mathrm{C}\right)$ & $\mathrm{TGA}(\boldsymbol{\mu m})$ \\
\hline PERTG - 1.200 & 1.200 & $120 \pm 20$ \\
PERTG - 900 & 900 & $4,7 \pm 0,15$ \\
\hline
\end{tabular}

Tabla V. Valores del tamaño de colonia perlítica, Tcolonia, para las dos temperaturas de austenización, $T^{\gamma}$

Table V. Values of size of pearlitic colonies, Tcolonia, by the two austenitizing temperatures, $T^{\gamma}$

\begin{tabular}{lrcc}
\hline Ensayo & $\mathbf{T}_{\gamma}\left({ }^{\circ} \mathbf{C}\right)$ & $\mathbf{T}^{\mathrm{a}}\left({ }^{\circ} \mathbf{C}\right)$ & $\mathbf{T}_{\text {colonia }}(\boldsymbol{\mu m})$ \\
\hline 57PER & 1.200 & 660 & $9,4 \pm 0,4$ \\
62PER & 900 & 660 & $4,7 \pm 0,5$ \\
\hline
\end{tabular}

\subsection{Efecto del TGA en el espaciado interlaminar de la perlita}

Por otro lado, se ha estudiado la influencia del TGA y la temperatura de descomposición isotérmica en el espaciado interlaminar de las colonias perlíticas. La figura 3 muestra las láminas de ferrita y cementita que constituyen la perlita en micrografías SEM de muestras con distintos valores de TGA $(120 \mu \mathrm{m}$ y $5 \mu \mathrm{m})$ pero igual temperatura de transformación isotérmica de $660^{\circ} \mathrm{C}$ (57PER y 62PER). Asimismo, la figura 3 también muestra el espaciado interlaminar en una micrografía de transmisión correspondiente a una muestra con TGA $=120 \mu \mathrm{m}$ y obtenida por descomposición isotérmica de la austenita a $560^{\circ} \mathrm{C}$ (59PER). Los resultados obtenidos se resumen en la tabla VI, observándose que si bien el espaciado interlaminar no depende del tamaño de grano austenítico previo, por el contrario presenta una marcada dependencia con la temperatura de descomposición isotérmica.

\subsubsection{Efecto de la temperatura de descomposición isotérmica sobre la fracción en volumen de perlita}

La figura 4 representa un esquema del diagrama de equilibrio $\mathrm{Fe}-\mathrm{C}$. El área sombreada, formada por la
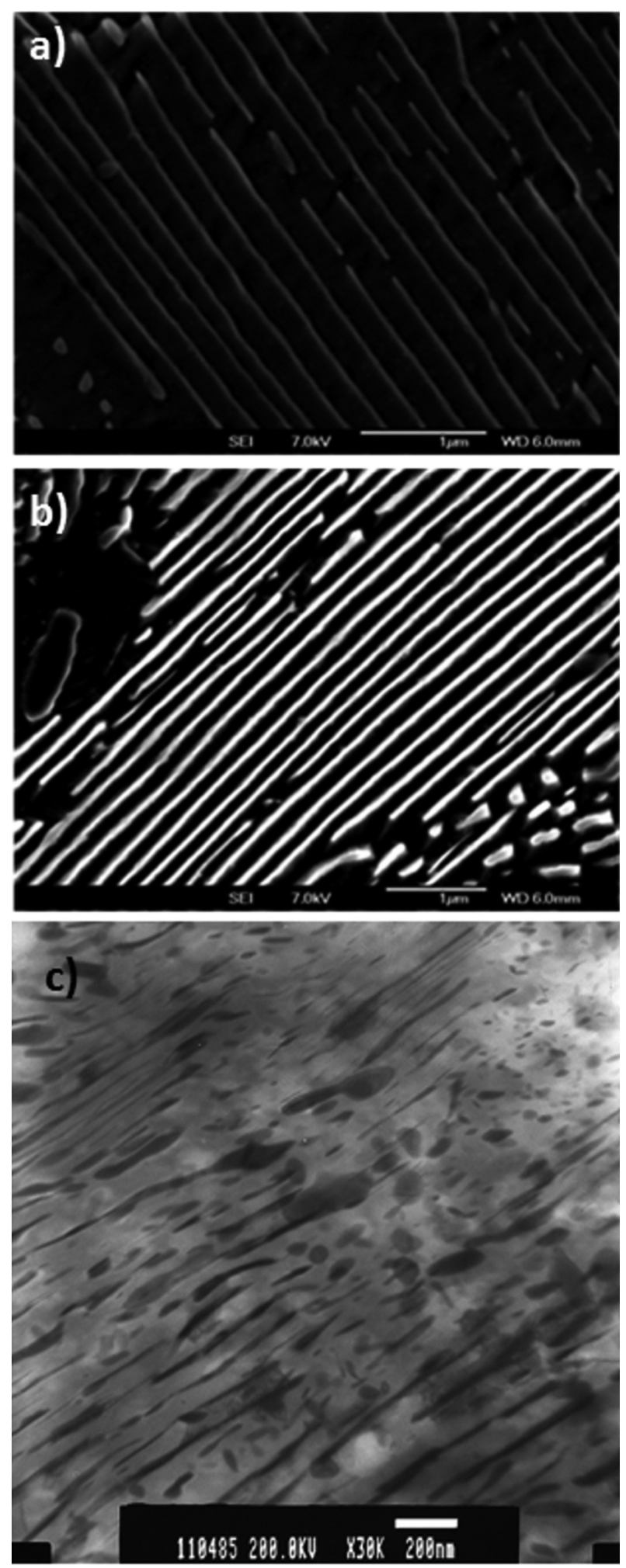

Figura 3. Micrografías SEM para la determinación del espaciado interlaminar de la muestra (a) 57 PER, (b) 62 PER y micrografía TEM para la muestra (c) 59PER.

Figure 3. SEM micrographs for the determination of interlaminar spacing of the sample (a) 57 PER, (b) 62 PER and TEM micrograph of the sample (c) 59PER. 
Tabla VI. Valores obtenidos para el espaciado interlaminar perlítico, $\sigma_{0}$

Table VI. Values obtained for the pearlitic
interlamellar spacing, $\sigma_{0}$

\begin{tabular}{lrcc}
\hline Ensayo & $\mathrm{T}^{\mathrm{r}}\left({ }^{\circ} \mathrm{C}\right)$ & $\mathrm{T}^{\mathrm{a}}\left({ }^{\circ} \mathbf{C}\right)$ & $\sigma_{\mathrm{o}}(\boldsymbol{\mu m})$ \\
\hline 57PER & 1.200 & 660 & $0,17 \pm 0,03$ \\
62PER & 900 & 660 & $0,17 \pm 0,03$ \\
59PER & 1.200 & 560 & $0,09 \pm 0,02$ \\
\hline
\end{tabular}

extrapolación de las líneas $\gamma / \gamma+\alpha$ y $\gamma / \gamma+\theta$, que representan la concentración de carbono en la intercara austenita-ferrita y austenita-cementita respectivamente, forma una región, o rango de temperaturas y composiciones, para las cuales la fase austenita está saturada simultáneamente con respecto a la ferrita y la cementita para la temperatura de descomposición isotérmica T (Extrapolación de Hultgren) [18 y 19].

Una austenita de composición $\overline{\mathrm{x}}$, cuando se enfría hasta la temperatura $\mathrm{T}^{\mathrm{P}}\left(\mathrm{Ae}_{1}>\mathrm{T}^{\mathrm{P}}>\mathrm{T}\right)$ de la figura 4, está sobresaturada con respecto a la fase ferrita, en ausencia de núcleos de cementita, es decir, en un hipotético diagrama de fases sin cementita (está por debajo de la línea $\gamma / \gamma+\alpha)$. El mismo acero no está, sin embargo, saturado con respecto a la cementita en un diagrama hipotético sin ferrita (está por encima de la línea $\gamma(\gamma+\theta)$, y la transformación $\gamma \rightarrow \gamma+\theta$ no tendría lugar hasta que no progrese la transformación austenita-ferrita lo suficiente como para que la austenita, que aún no se ha transformado, se enriquezca con el carbono que expulsa la ferrita recién formada, hasta que la línea $\gamma / \gamma+\theta$ corte la línea de la temperatura $\mathrm{T}^{\mathrm{P}}$.

Como se ha indicado anteriormente, el área rayada por la extrapolación de Hultgren muestra la zona donde la austenita está saturada con respecto a ambas fases, ferrita y cementita, en el caso de hipotéticos diagramas de equilibrio independientes. Dentro de esta región, la reacción posible sería la descomposición de la austenita en un producto eutectoide $\alpha+\theta$, es decir, perlita.

Dicha reacción comenzaría por la nucleación de la cementita, quedando la austenita con una concentración marcada por la línea $\gamma / \gamma+\theta$. A continuación, y debido a que la austenita poseería una concentración en carbono $\mathrm{x}^{\gamma \theta}$ (intersección de $\mathrm{T}^{\mathrm{P}}$ con $\gamma(\gamma+\theta)$ alrededor del núcleo de cementita menor que la concentración del eutectoide, es posible la aparición de ferrita.

Esta segunda reacción llevaría a un enriquecimiento local en carbono de la austenita, que pasaría a tener una concentración alrededor de esta ferrita recién formada de $\mathrm{x}^{\gamma \alpha}$ (intersección de $\mathrm{T}^{\mathrm{P}} \operatorname{con} \gamma / \gamma+\alpha$ ), dando lugar a la formación de otro núcleo de cementita que empobrecería la austenita hasta una concentración $\mathrm{x}^{\gamma \theta}$. Así, sucesivamente, se van formando las distintas láminas de ferrita y cementita que constituyen la perlita.

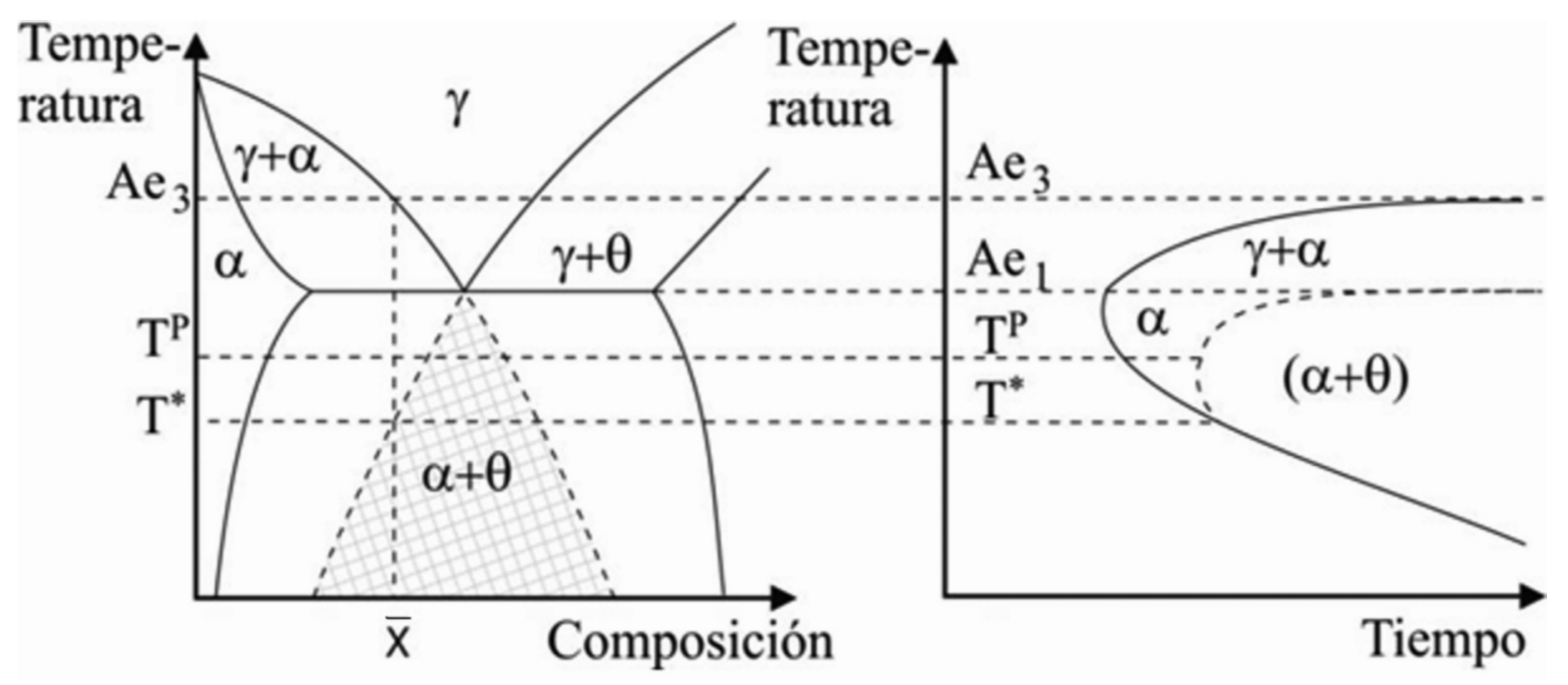

Figura 4. Extrapolación de Hultgren de las líneas de solubilidad que marca la concentración de las intercaras austenita-ferrita y austenita-cementita en un diagrama Fe-C. La región sombreada indica donde es posible encontrar perlita.

Figure 4. Hultgren extrapolation of austenite-ferrite and austenite-cementite tie-lines in a $\mathrm{Fe}-\mathrm{C}$ diagram. Pearlite is formed in the shadow area. 
En el diagrama de la figura 4 se observa que existe una temperatura, $\mathrm{T}^{*}$, para la cual la austenita con el contenido en carbono nominal del acero está saturada simultáneamente con la ferrita y cementita. Por tanto, toda la austenita transformará a perlita, sin formar ferrita proeutectoide previamente, aunque la composición nominal del acero sea hipoeutectoide. La fracción de volumen de la perlita depende, entonces, no sólo del contenido medio en carbono del acero, sino también de la temperatura de descomposición isotérmica de la austenita ${ }^{[20]}$. Cuanto más baja sea esta temperatura, la fracción de perlita será mayor.

El razonamiento anterior nos permite establecer las ecuaciones (3) y (4) para evaluar, aproximadamente, la cantidad de ferrita y perlita que se forma, en equilibrio, en función del diagrama de fases:

Ae3 $>$ T > Ae1 $(\mathrm{VF}>0$ y VP $=0)$ :

$$
\begin{gathered}
V_{F}=\frac{x^{\gamma \alpha}-\bar{x}}{x^{\gamma \alpha}-x^{\alpha \gamma}} \\
V_{P}=0
\end{gathered}
$$
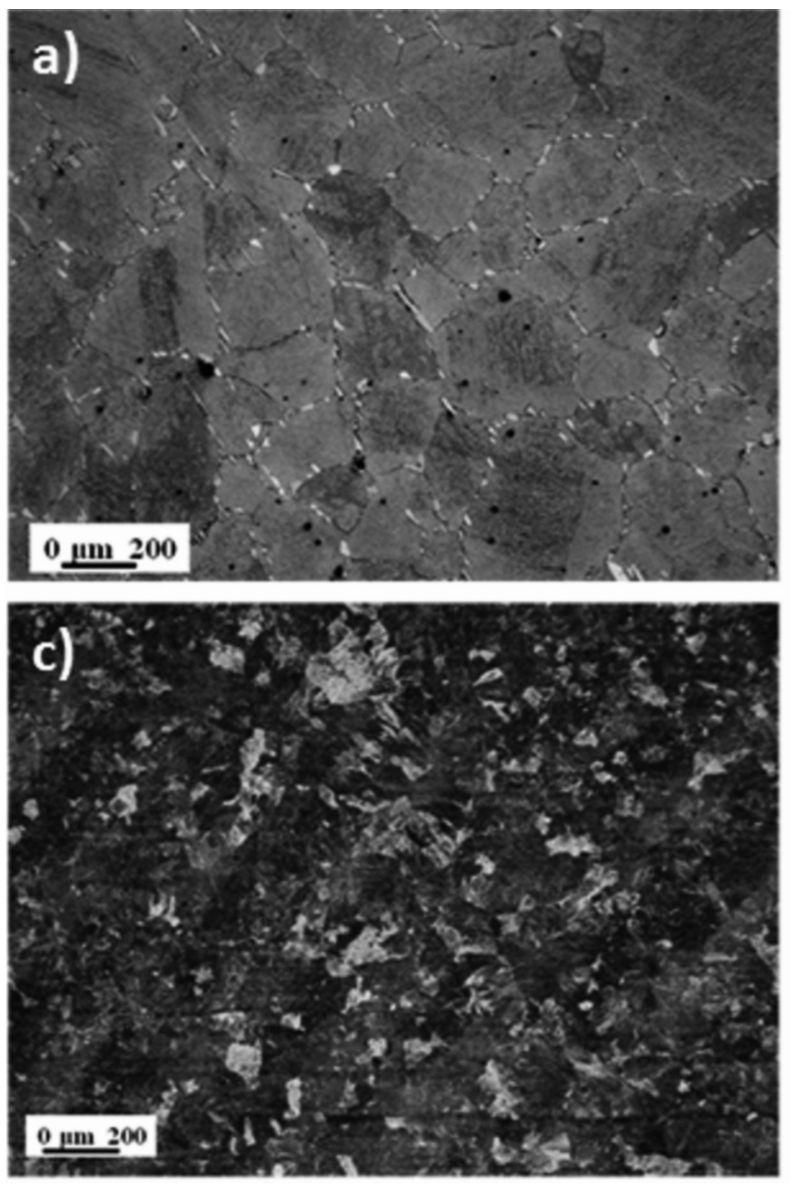

Figura 5. Micrografías ópticas para las muestras

$$
\begin{gathered}
T<\operatorname{Ae} 1(\mathrm{VF}>0 \text { y } V P>0): \\
V_{F}=1-V_{P}=\frac{x^{\gamma \theta}-\bar{x}}{x^{\gamma \theta}-x^{\alpha \gamma}} \\
V_{P}=\frac{\bar{x}-x^{\alpha \gamma}}{x^{\gamma \theta}-x^{\alpha \gamma}}
\end{gathered}
$$

donde $\mathrm{V}_{\mathrm{F}}$ es la fracción de volumen de ferrita, $\mathrm{V}_{\mathrm{P}}$ es la fracción de volumen de perlita, $\mathrm{x}^{\alpha \gamma}$ es la concentración en carbono de la línea $\alpha / \gamma+\alpha$, $x^{\gamma \alpha}$ es la concentración en carbono de la línea $\gamma / \gamma+\alpha$, y $x^{\gamma \theta}$ es la concentración en carbono de la línea $\gamma / \gamma+\theta$.

De esta forma se cumple que, para la temperatura $A e_{1}$, donde $x^{\gamma \alpha}=x^{\gamma \theta}$, las ecuaciones de $V_{F}$ para $\mathrm{T}>\mathrm{Ae}_{1}$ y $\mathrm{T}<\mathrm{Ae}_{1}$ convergen al mismo valor en $\mathrm{Ae}_{1}$. Además, la ecuación (4) tiene en cuenta la situación anteriormente descrita donde existe una temperatura, $\mathrm{T}^{*}$, para la cual $\mathrm{V}_{\mathrm{F}}=0$, es decir, la temperatura en donde se cumple que $\overline{\mathrm{x}}=\mathrm{x}^{\gamma \theta}$.

Con idea de validar esta aproximación teórica, se realizaron una serie de tratamientos térmicos descritos
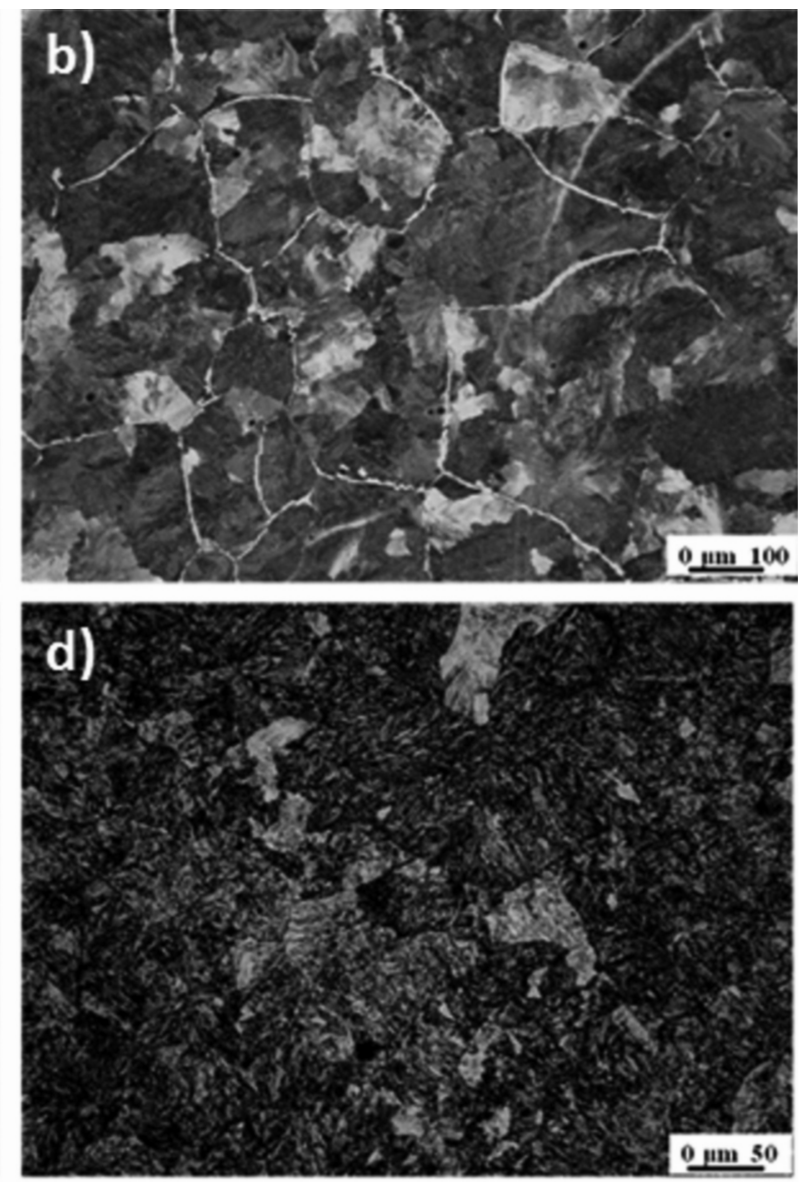

Figure 5. Optical micrographs for the samples (a) 55PER, (b) 57PER, (c) 58PER y (d) 59PER. 
en la tabla III y representados en la figura 1. Los resultados del análisis metalográfico se muestran en la figura 5. Se ha encontrado que la fracción de volumen perlítica es nula para las muestras cuya descomposición isotérmica se ha llevado a cabo a mayor temperatura $\left(\mathrm{T}=715^{\circ} \mathrm{C}\right)$ observándose en este caso tan sólo las fases austenítica y ferrítica. Al disminuir la temperatura hasta $695^{\circ} \mathrm{C}$ comienzan a aparecer colonias perlíticas en buen acuerdo con el diagrama de fases de la figura 1 . Para una temperatura inferior a $610^{\circ} \mathrm{C}$, el caso de la figura 5 (d) corresponde a $560^{\circ} \mathrm{C}$, la fracción en volumen de perlita alcanza el $100 \%$.

Efectivamente, en la figura 6 se representa cómo evoluciona la fracción de volumen de perlita obtenida experimentalmente con el grado de sub-enfriamiento respecto a la temperatura eutectoide $(\Delta \mathrm{T})$, es decir, a medida que la temperatura del isotérmico disminuye. En la figura 6 se ha representado también la evolución de la fracción de volumen de perlita calculada de acuerdo con las ecuaciones anteriores.

\subsubsection{Efecto del TGA en la cinética de transformación perlítica}

Para obtener información detallada de la cinética de transformación isotérmica de la austenita en perlita se estudiaron las curvas dilatométricas de probetas tratadas isotérmicamente con TGA de $120 \mu \mathrm{m}$ y $5 \mu \mathrm{m}$. Asimismo, se realizaron ensayos interrumpidos para evaluar la fracción de perlita en función del tiempo y de la temperatura. La figura 7 muestra los resultados obtenidos para la cinética de formación de perlita para los dos tamaños de grano austeníticos de partida estudiados. Se puede concluir de esta figura que la cinética de formación de perlita es más rápida para valores de TGA bajos. La figura 8 ilustra con un ejemplo las microestructuras obtenidas por ensayos isotérmicos interrumpidos para el caso de $695^{\circ} \mathrm{C}$.

Estos resultados son consecuentes con el hecho de que la formación de perlita puede tener lugar sobre la intercara austenita-ferrita, o austenita-austenita (Fig. 9). En este sentido, valores de TGA altos implican una superficie de borde de grano austenítico muy reducida en comparación con su volumen, lo que dificulta tanto la nucleación de ferrita alotriomórfica como la de perlita, de forma que la cinética se ve sensiblemente ralentizada.

\subsubsection{Mecanismos de formación de perlita}

Aunque existe un alto grado de acuerdo sobre los lugares de nucleación de la perlita, se observa una cierta

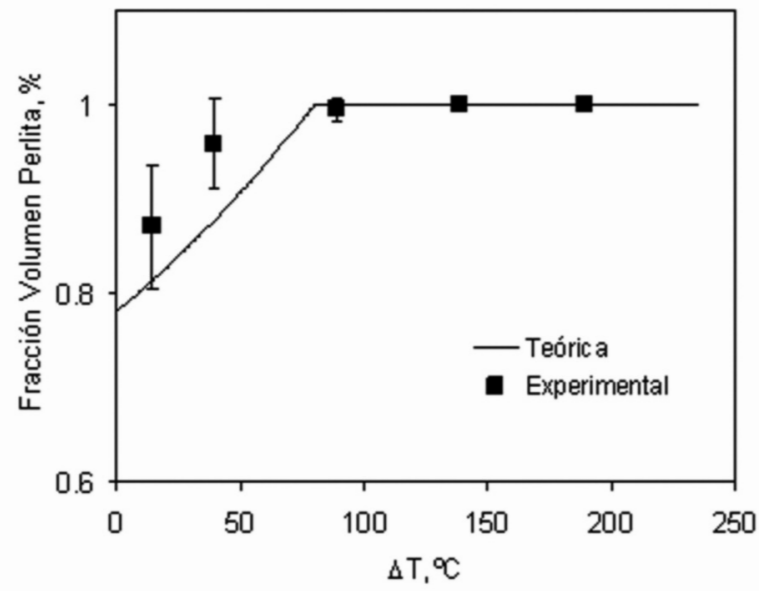

Figura 6. Evolución del porcentaje de perlita con el grado de subenfriamiento.

\section{Figure 6. Pearlite volume fraction evolution with undercooling.}

controversia en la literatura científica en relación a los mecanismos de crecimiento de perlita. En una aleación Fe-C-Mn como el caso de estudio, se pueden activar dos mecanismos distintos: tanto la difusión de carbono como la difusión de manganeso. Algunos autores ${ }^{[8]}$ han supuesto que durante el crecimiento de la perlita se produce un reparto de los diferentes elementos aleantes entre la cementita y la ferrita, de forma que el crecimiento es por mecanismos de equilibrio local (MELP), controlado por el elemento que difunda más lentamente, en este caso el manganeso. Otros autores ${ }^{[21]}$ sostienen, por el contrario, que el mecanismo de crecimiento, debido al rango de temperaturas en el que se produce la transformación perlítica, debería ser controlado únicamente por la difusión del carbono, es decir, por mecanismos de paraequilibrio, pues la difusión de elementos como el manganeso es muy baja a esta temperatura. En detrimento de esta última hipótesis cabría decir que la difusión de manganeso no se produce en volumen como la de carbono, sino a lo largo de la intercara de la transformación austenita-perlita, donde la distancia que han de recorrer los elementos aleantes es muy pequeña, y además su difusividad es considerablemente mayor. Con lo cual, aunque la temperatura de estudio sea baja para suponer la difusión de elementos más pesados que el carbono, puede que sea lo suficiente para considerar la difusión de corto alcance por la intercara. Además, podría ser factible el hecho de que existiera una transición entre los dos mecanismos. Es decir, que a altas temperaturas predomine el crecimiento de perlita controlado por difusión de manganeso en la intercara perlita-austenita, y que por el contrario, a bajas temperaturas sea la difusión en carbono el mecanismo predominante. 

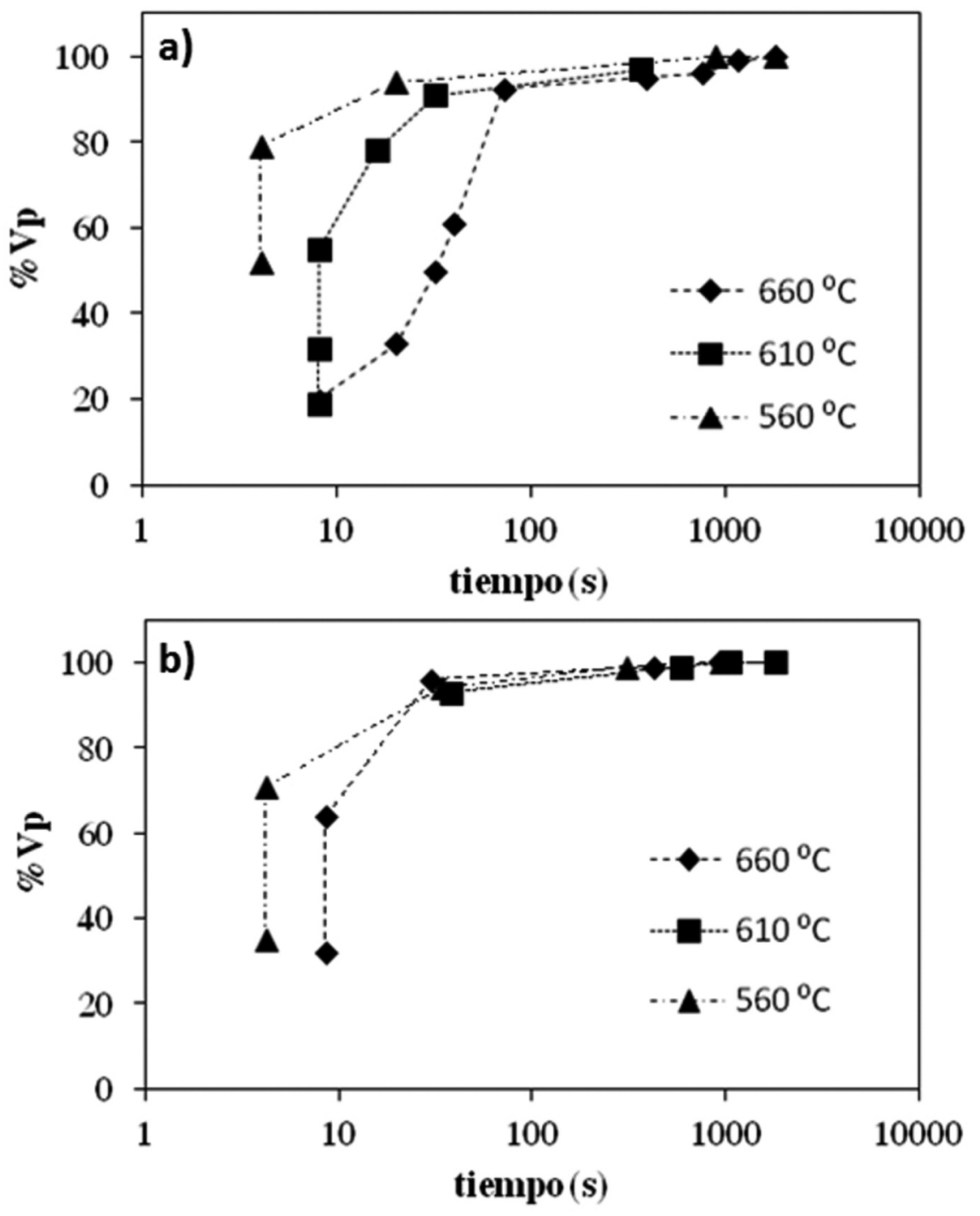

Figura 7. Cinética de formación de perlita para distintas temperaturas de tratamiento isotérmico para muestras con TGA de (a) $120 \mu \mathrm{m}$ y (b) $5 \mu \mathrm{m}$. Datos extraídos de las curvas dilatométricas.

Figure 7. Pearlite kinetics for different isothermal temperatures from TGA values of (a) $120 \mu \mathrm{m}$ and (b) $5 \mu \mathrm{m}$. Data extracted from dilatometric curves.

Asumiendo esta última hipótesis, es decir, determinar el rango de temperaturas en el que predomina cada uno de los dos mecanismos que se proponen en la literatura para la formación de perlita, se han comparado los datos experimentales con los valores obtenidos a través de un modelo teórico cinético. Por tanto, utilizando el modelo desarrollado por Capdevila y colaboradores ${ }^{[22]}$, se ha calculado la cinética de formación de perlita en el rango de temperaturas comprendido entre 660 y $560^{\circ} \mathrm{C}$ considerando ambos mecanismos (difusión de carbono y difusión de manganeso). Dichos valores se han comparado con los datos experimentales que hemos obtenidos en nuestro caso y que aparecen recogidos en la figura 8. El resultado de la comparación de las distintas curvas cinéticas se representa en la figura 10.

Se puede concluir, que en el rango de temperaturas comprendido entre $560^{\circ} \mathrm{C}$ y $660^{\circ} \mathrm{C}$, el mecanismo responsable del crecimiento de perlita es la difusión en volumen de carbono ya que los datos experimentales se ajustan con un alto grado de concordancia a las curvas teóricas que predice el modelo asumiendo un mecanismo de difusión del carbono. Por el contrario, los valores de cinética que predice el modelo suponiendo la difusión del manganeso no concuerdan con los resultados experimentales de nuestro caso. 

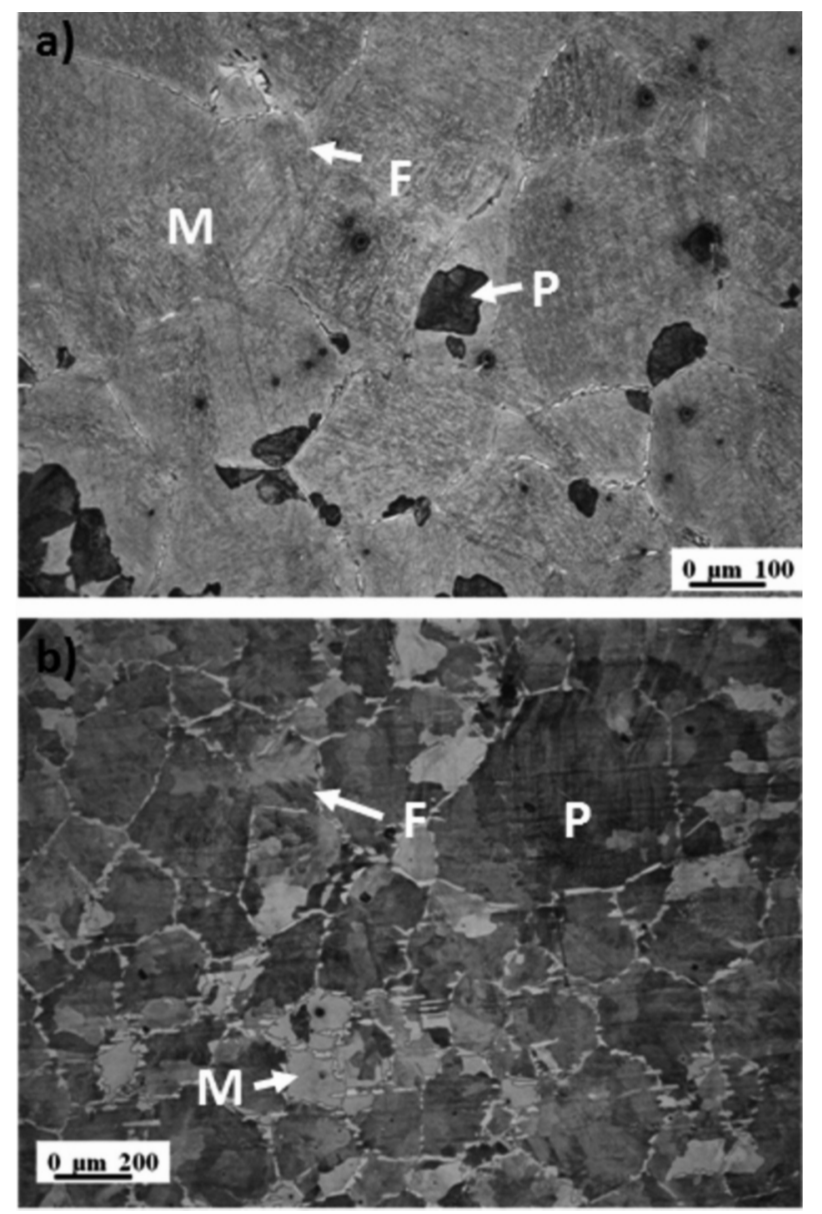

Figura 8. Micrografía óptica de la muestra 56 PER $\left(T=695^{\circ} \mathrm{C}\right)$ en un tiempo de $(a) t=36 \mathrm{~s}$ $y(b) t=1.055 \mathrm{~s}$. $M$ indica martensita; $F$ indica ferrita; $P$ indica perlita

Figure 8. Optical micrographs for the sample $56 \operatorname{PER}\left(T=695^{\circ} \mathrm{C}\right)$ after holding for (a) $t=36 \mathrm{~s}$ and $(b) t=1055 \mathrm{~s}$. $M$ stands for martensite; $F$ stands for ferrite; $P$ stands for pearlite.

A su vez, también se observa que si bien el tamaño de grano austenítico afecta a la cinética de formación de perlita, parece que no tiene gran influencia en el mecanismo de crecimiento ya que para los dos tamaños de grano austeníticos de partida el mecanismo predominante es el mismo: difusión de carbono en volumen.

De la figura 10 se puede concluir también que la transformación de austenita en perlita más rápida ocurre a una temperatura de descomposición isotérmica $\mathrm{T}=560{ }^{\circ} \mathrm{C}$, mientras que a temperaturas superiores de descomposición, $\mathrm{T}=660^{\circ} \mathrm{C}$, la transformación ocurre más lentamente.

Sin embargo, es posible que a temperaturas de descomposición isotérmica más altas de $660^{\circ} \mathrm{C}$, la partición de manganeso sea el mecanismo que con-
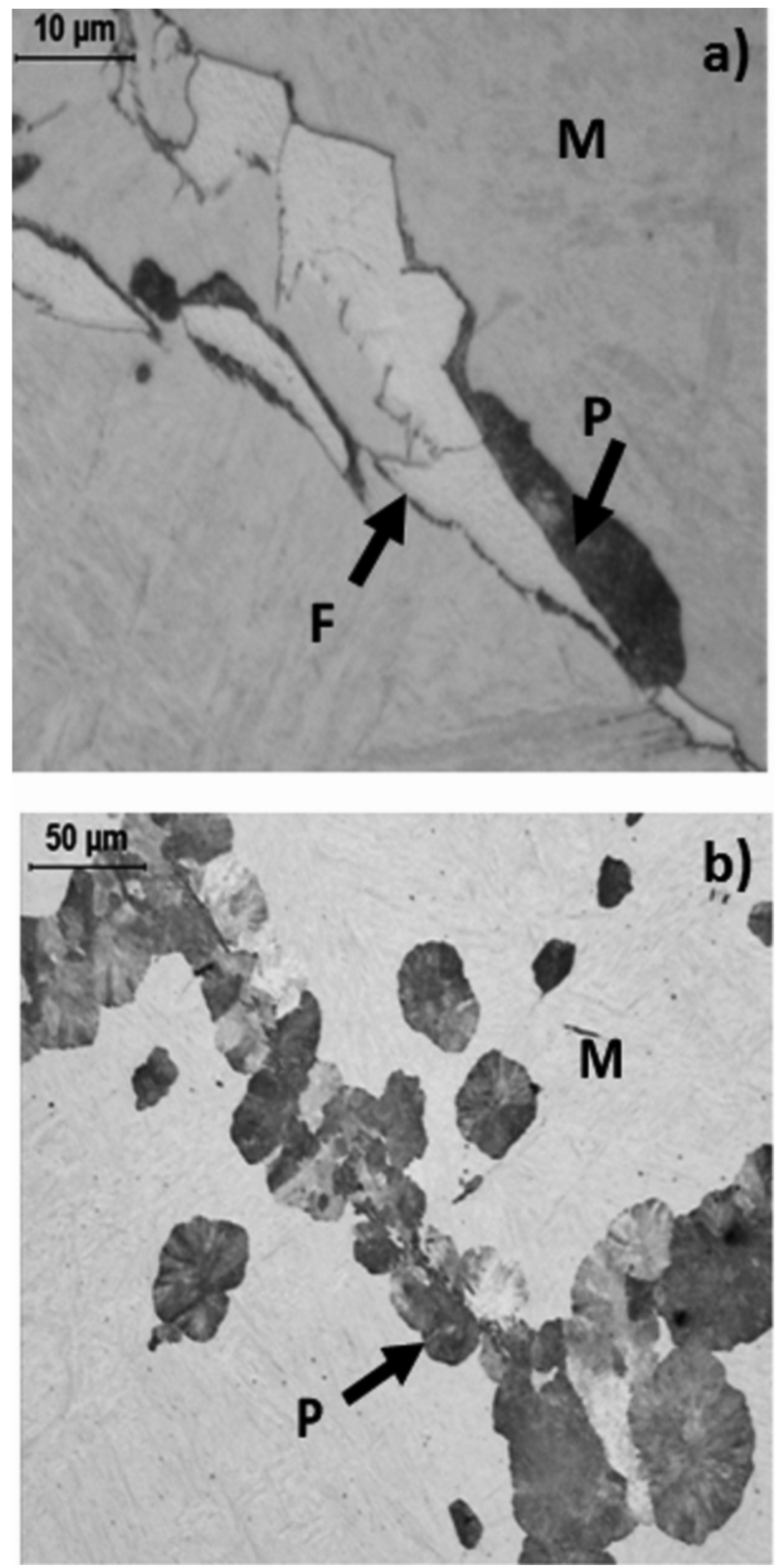

Figura 9. Nucleación de perlita en (a) intercara ferrita-austenita $\left(T=695^{\circ} \mathrm{C}\right.$ después de $\left.36 \mathrm{~s}\right)$, y (b) intercara austenita-austenita $\left(T=560{ }^{\circ} \mathrm{C}\right.$ después de $5 \mathrm{~s}$ ). $\mathrm{M}$ indica martensita; $\mathrm{F}$ indica ferrita; $P$ indica perlita.

Figure 9. Pearlite nucleation on (a) ferrite-austenite interface $\left(T=695^{\circ} \mathrm{C}\right.$ after $\left.36 \mathrm{~s}\right)$, and (b) austenite - austenite interface $\left(T=560^{\circ} \mathrm{C}\right.$ after 5 s). $M$ stands for martensite; $F$ stands for ferrite; $P$ stands for pearlite.

trole el crecimiento de perlita. Para ello, se analiza por EDX en el microscopio TEM la variación de manganeso entre la cementita y la ferrita a través de la intercara perlita-austenita, en una muestra tratada isotérmicamente a $688^{\circ} \mathrm{C}$ y donde la transfor- 

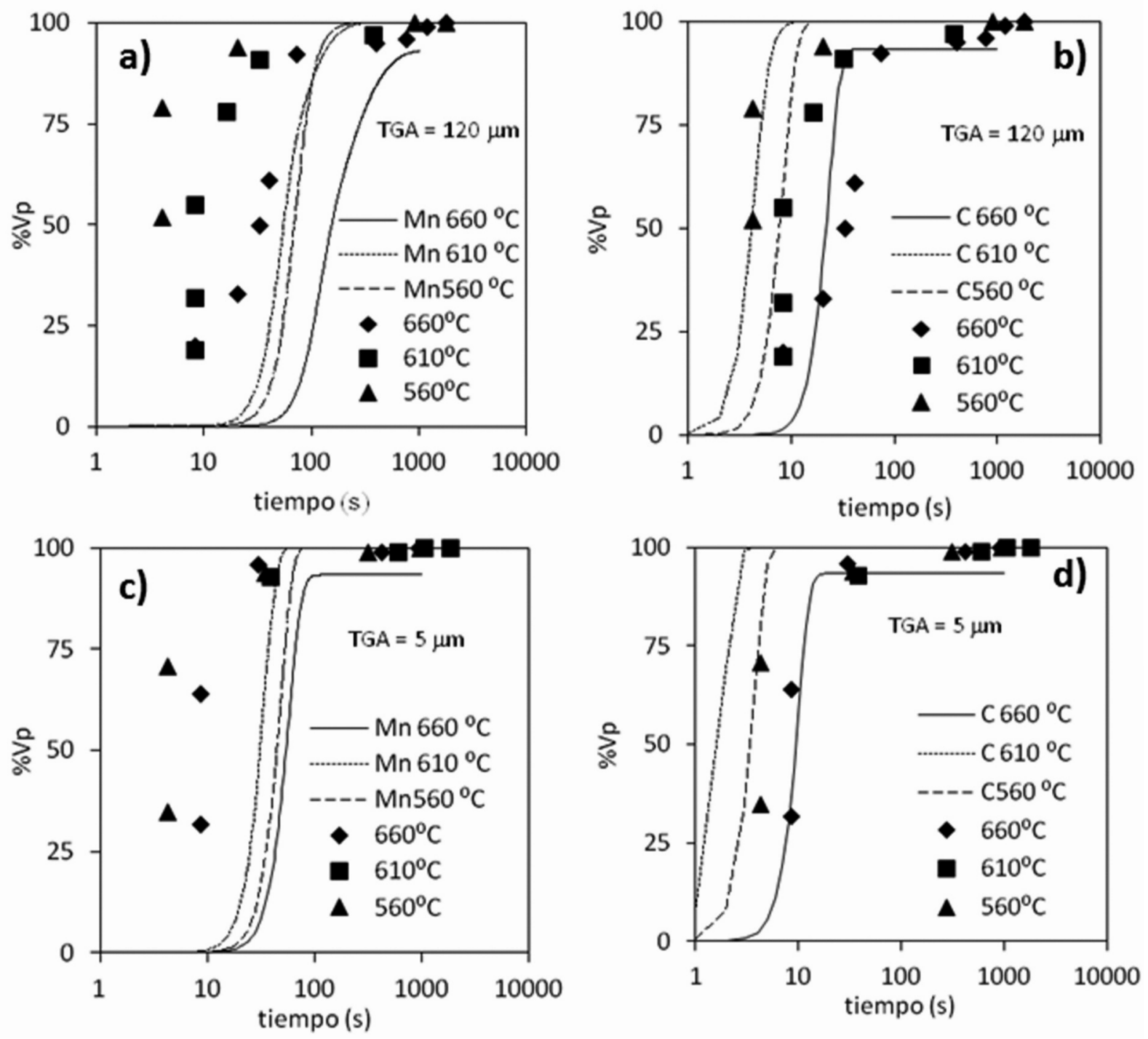

Figura 10. Evolución de la fracción de perlita suponiendo un mecanismo de difusión de manganeso por la intercara y un mecanismo de difusión en volumen de $C$ para la muestra con TGA $=120 \mu \mathrm{m}$ ( $a$ y b) y para la muestra con TGA $=5 \mu \mathrm{m}$ ( $c$ y d). Datos derivados de las curvas dilatométricas.

Figure 10. Evolution of pearlitic fraction assuming interface manganese diffusion and volumen carbon diffusion mechanisms for sample with AGS $=120 \mu \mathrm{m}$ ( $a$ and b) and with AGS $=5 \mu \mathrm{m}$ (c and d). Data extracted from dilatometric curves.

mación perlítica no se ha completado. De esta manera es posible estudiar la composición del frente de avance de la perlita en la ferrita, en la cementita y en la martensita (austenita), y determinar el contenido de manganeso en las diferentes fases para establecer si se produce reparto de este constituyente o no. La figura 11 muestra la intercara perlita-austenita analizada, y el perfil de manganeso a través de esa intercara en la cementita y en la ferrita. El análisis de composición se hace desde el interior de la ferrita (o cementita) hacia la austenita, a la que corresponde la posición 4. La posición 3 se toma en la intercara ferrita (o cementita)/austenita (Fig. 11). De estos resultados se puede concluir que existe difusión de manganeso desde la ferrita hacia la cementita. El porcentaje de manganeso en masa en la ferrita es unas 5 veces menor que en la cementita. En ambos casos el porcentaje de manganeso en la austenita está en torno a 0,7 que es la composición nominal del acero.

La figura 12 muestra la validación de la cinética de formación de perlita durante el tratamiento iso- 

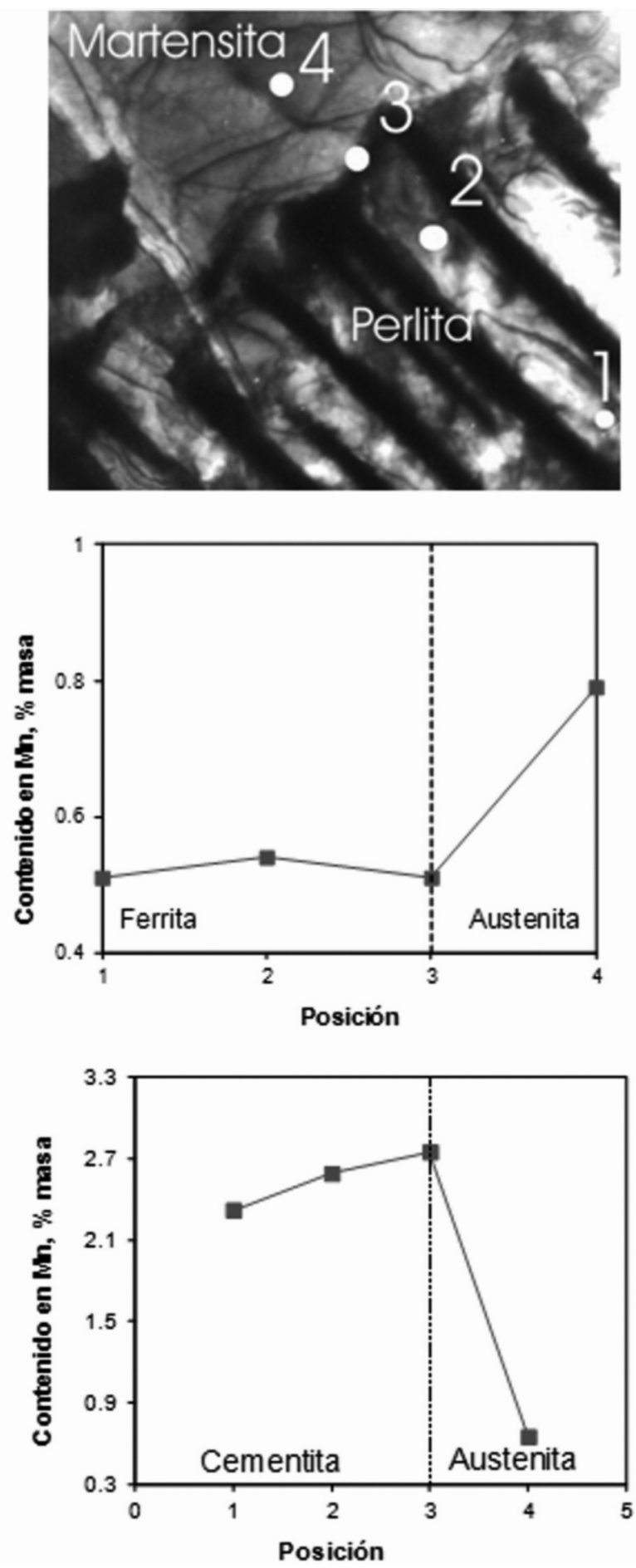

Figura 11. Análisis por EDX de la concentración de manganeso a través de la intercara perlita-austenita: (a) puntos de análisis, (b) perfil de concentración en la ferrita y cementita.

Figure 11. EDX analysis of manganese concentration through the austenite-pearlite interface: (a) point analyzed, (b) composition profile in ferrite and cementite. térmico a $680^{\circ} \mathrm{C}$. La validación se ha llevado a cabo comparando los datos de la fracción de volumen de perlita obtenidos por el modelo desarrollado por Capdevila y colaboradores ${ }^{[22]}$, con los datos experimentales obtenidos por tratamientos interrumpidos. Se puede concluir que a temperaturas del orden de $688^{\circ} \mathrm{C}$ el mecanismo de crecimiento de perlita es el controlado por la difusión de manganeso.

\section{CONCLUSIONES}

- Se han estudiado los mecanismos de descomposición isotérmica de la austenita en perlita en un acero de composición 0,44C-0,73Mn mediante microscopía óptica, SEM, TEM y dilatometría. Se ha observado que el tamaño de grano y el tamaño medio de las colonias perlíticas dependen fuertemente de la temperatura de austenización $\left(\mathrm{T}^{\gamma}\right)$, aumentando ambos parámetros a medida que aumenta $T^{\gamma}$, sin embargo, parece que el espaciado interlaminar está controlado básicamente por la temperatura de la transformación perlítica $\mathrm{T}$ y no por $\mathrm{T} \gamma$.

- También se ha observado que la cinética es, para todas las temperaturas, más rápida para un tamaño de grano austenítico de partida pequeño que para un tamaño de grano austenítico de partida grande. Este comportamiento se debe a que al ser la perlita una fase que nuclea en la intercara ferrita-austenita y/o en la superficie de borde de grano austenítico se favorece la formación de perlita para un tamaño de grano austenítico de partida pequeño debido a que presenta mayor relación superficie/volumen de sitios de nucleación.

- Se ha comprobado que la transformación más rápida de austenita en perlita ocurre a una temperatura de descomposición isotérmica $\mathrm{T}=560^{\circ} \mathrm{C}$, mientras que a temperaturas superiores de descomposición la transformación ocurre más lentamente.

- La fracción de volumen de perlita que se obtiene tras la descomposición total de la austenita aumenta al disminuir la temperatura de descomposición isotérmica, alcanzándose una cantidad de perlita de prácticamente el $100 \%$ para temperaturas iguales o inferiores a $610^{\circ} \mathrm{C}$.

- Finalmente, comparando los datos experimentales de la cinética de formación de perlita con los resultados de un modelo teórico desarrollado por Capdevila y colaboradores se concluye que el mecanismo que controla la formación de perlita en el rango de temperaturas de $660^{\circ} \mathrm{C}$ a $560{ }^{\circ} \mathrm{C}$ 


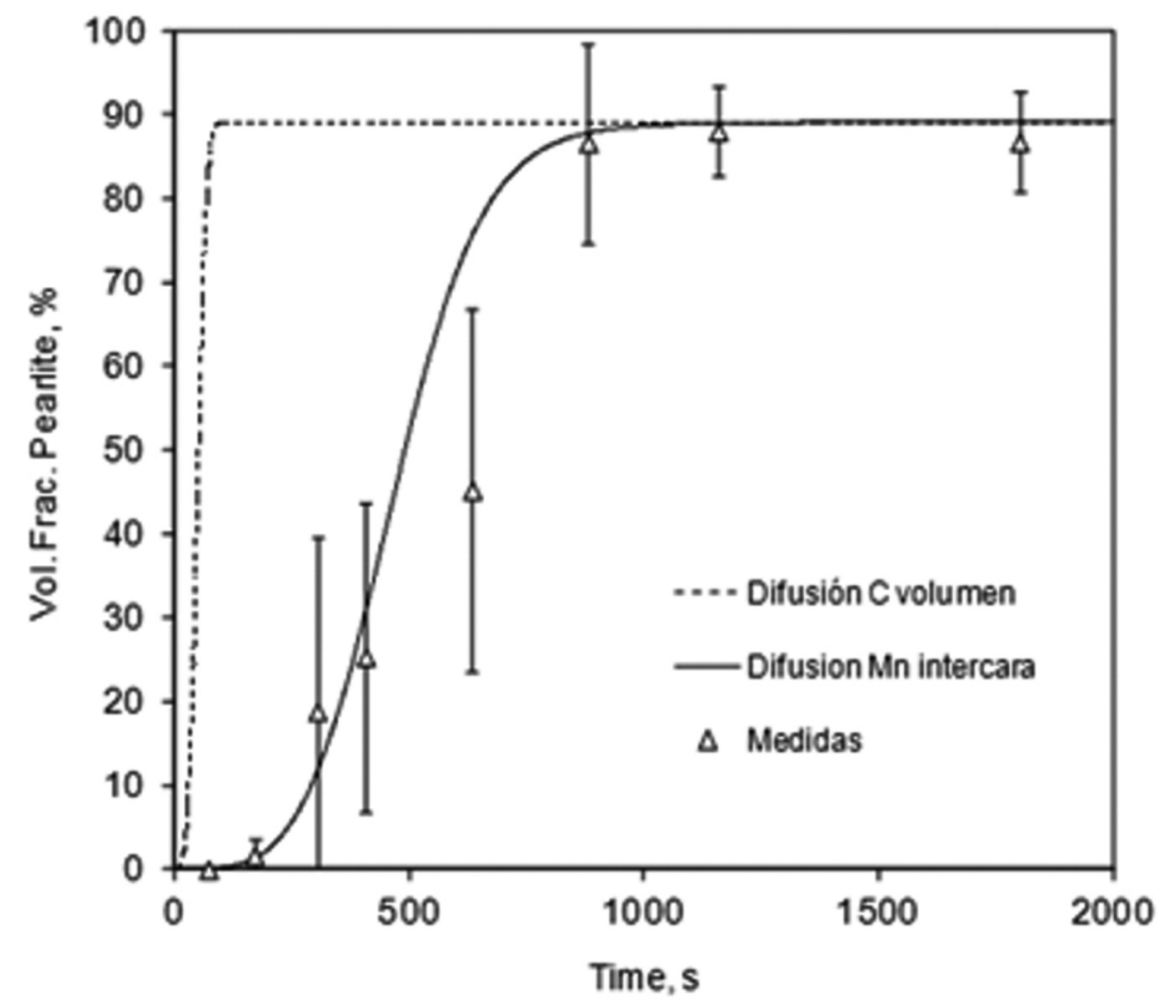

Figura 12. Evolución de la fracción de perlita a $688^{\circ} \mathrm{C}$ suponiendo un mecanismo de difusión en volumen de $\mathrm{C}$ y un mecanismo por la intercara de manganeso.

Figure 12. Evolution of pearlitic fraction at $688^{\circ} \mathrm{C}$ assuming volume carbon diffusion or interface manganese diffusion mechanisms.

es la difusión en volumen de carbono a través de la intercara austenita-ferrita y que el tamaño de grano afecta a la cinética de formación pero no al mecanismo.

\section{REFERENCIAS}

[1] J. Fridberg y M. Hillert, Acta Metallurgica 18 (1970) 1.253-1.260.

[2] C. Capdevila, F.G. Caballero y C. García de Andrés, Acta Mater. 50 (2002) 4.629-4.641.

[3] J. Herian y K. Aniolek, Archives of Materials Science and Engineering 31 (2) (2008) 83-86.

[4] S. Allain, M. Gouné, O. Bouaziz, E. Kassir, P. Barges y L. Jantzen, Mater. Sci. 46 (2011) 2.7642.770 .

[5] X. Zhang, A. Godfrey, X. Huang, N. Hansen y Q. Liu, Acta Mater. 59 (2011) 3.422-3.430.

[6] K. George, Steels - Processing, Structure, and Performance, ASM International, Ohio, EE.UU., 2005, pp. 281-285.
[7] R.W.K. Honeycombe y H.K.D.H. Bhadeshia, Steels, Microstructures and Properties, Butterworths-Heinemann (Elsevier), London, England, 2006, p. 52.

[8] N. Ridley, Phase Transformation in Ferreous Alloys, TMS-AIME, Warrendale, EE.UU., 1984, p. 201.

[9] C. Capdevila, F.G. Caballero y C. García de Andrés, Scripta Materialia 44 (2001) 593. 600.

[10] MTDATA National Physical Laboratory, at www.npl.co.uk/mtdata/ (acceso Agosto 2011), Teddington, England, 2003.

[11] C. García de Andrés, M.J. Bartolomé, C. Capdevila, D.S. Martín, F.G. Caballero y V. López, Mater. Charact. 46 (2001) 389-398.

[12] IMAGE TOOL, University of Texas, at ddsdx.uthscsa.edu/dig/itdesc.html (acceso Octubre 2011), San Antonio, EE.UU., 2002.

[13] O. Grässel, L. Krüger, G. Frommeyer y L. W. Meyer, International Journal of Plasticity 16 (2000) 1.391-1.409. 
[14] F.G. Caballero, C. García de Andrés y C. Capdevila, Mater. Charact. 45 (2000) 111-116.

[15] E.E. Underwood, Quantitative Stereology, Addison-Wesley Reading, Massachusetts, EE.UU., 1970.

[16] S.A. SALTYKOV, Stereometric Metallography, 2nd Ed., Metallurgizdat, Moscow, 1958.

[17] Standard Test Method for Determining Volume Fraction by Systematic Manual Point Count E 562-02, ASTM International, PA, EE.UU.

[18] R.F. Mehl y W.C. Hagel, Progress in Metal Physics, Vol. 6, Pergamon Press, New York, EE.UU., 1956, p. 74.
[19] R.F. Mehl y W.C. Hagel, Decomposition of austenite by diffusional processes, V.F. Zackay y H.I. Aaronson (Eds.), Interscience, New York, EE.UU., 1962, p. 131.

[20] B. Thomas y M. Guttmann, The Book of steels, G. Béranger, G. Henry y G. Sanz (Eds.), SOLLAC, IRSID, Paris, France, 1996, p. 131.

[21] M. Hillert, Conferencia Internacional Solid Solid Phase Transformation, H.I. Aaronson et al. (Eds.), TMS-AIME, Warrendale, EE.UU., 1982, p. 789.

[22] C. Capdevila, F.G. Caballero y C. García de Andrés, Scripta Mater. 50 (2004) 175-177. 